lated to attempts to induce RA in the rumen in vitro and in vivo, and understanding the relative importance of $\mathrm{RA}$ and $\mathrm{M}$ in the rabbit caecum.

The affinity for $\mathrm{H}_{2}$ of $\mathrm{RA}$ is lower than that of $M$ but the importance of RA in the hindgut has been related to the higher amounts of free amino acids, mucins and bile salts, inducive and/or inhibitory for RA and $M$ respectively. Batch incubations of sheep rumen contents with these compounds added did not stimulate RA although selective inhibition of $M$ was demonstrated, accompanied however by increased propionate production [2,3]. Addition of Peptrostreptococcus productus ATCC 35244 [4] or methanol [5] together with 2-bromoethane sulfonic acid (BES) to sheep rumen contents in vitro increased acetate production through RA. Such experiments in vivo are excluded however because of the very fast adaptation of the rumen to BES [5]. Use of a similar combination with a bacteriocin-like inhibitor of $M$ resulted in similar results in vitro and in vivo (Nollet et al, in preparation). Also, direct introduction of frozen and thawed cattle hindgut contents to a sheep rumen did not affect rumen fermentation stoichiometry in vitro [5].

$\mathrm{RA}$ is a major characteristic of the caecal fermentation in young suckling rabbits, producing significant amounts of VFA with little or no $M$. Subject to a litter effect, RA is replaced gradually and partially by $M$ with the increasing intake of solid feed [6]. However, caecal RA was clearly present in non-fasted rabbits only [7]. In contrast to the sheep caecum [8], monensin increased non fasted rabbit caecal $\mathrm{M}$ in vitro, accompanied by a decrease in butyrogenesis. Depression of $\mathbf{M}$ was observed with BES (Piattoni et al, in preparation). The results suggest that rabbit caecal RA is inhibited by monensin, although such an effect was not apparent from viable counts of bacteria active in RA. It is suggested that caecal bacteria capable of RA are different in sheep and rabbits.

1. Demeyer D, De Graeve K, Durand M, Stevani J (1989) Acta Vet Scand Supp 86, 6875

2. Demeyer DI, Fiedler D, De Graeve KG (1996) Reprod Nutr Dev 36, 233-240

3. Immig, I (1997) Arch Anim Nutr (submitted)

4. Nollet L, Demeyer D, Verstreaete W (1997) Appl Environ Microbiol 63, 194200

5. Immig I, Demeyer D, Fiedler D, Van Nevel C, Mbanzamihigo L (1996) Arch Anim Nutr 49, 363-370

6. Piattoni F, Demeyer D, Maertens L (1996) Reprod Nutr Dev 36, 253-261

7. Piattoni F, Demeyer D, Maertens L (1997) World Rabbit Sci (in press)

8. Mbanzamihigo L, Van Nevel CJ, Demeyer D (1996) Anim Feed Sci Technol 62, 215 228

\section{Characteristics of $\mathrm{H}_{2} / \mathrm{CO}_{2}$ meta-} bolism in acetogenic bacteria from the human colon. M Leclerc ${ }^{1}$, A Bernalier ${ }^{1,2}\left({ }^{l} I N R A\right.$, Laboratoire de Nutrition et Sécurité Alimentaire, Domaine de Vilvert, 78352 Jouy-en-Josas cedex, France; ${ }^{2} I N R A$, Laboratoire de Microbiologie, Centre de Recherche de ClermontTheix, 63122 Saint-Genès-Champanelle, France)

In the human colon, the fermentation of substrates which are not absorbed in the upper- digestive tract, leads to the production of short chain fatty acids (mainly acetate, propionate and butyrate) and 
gases $\left(\mathrm{H}_{2}, \mathrm{CO}_{2}\right.$ and, in some cases $\left.\mathrm{CH}_{4}\right)$. A large part of the hydrogen produced is re-utilized in situ by hydrogenotrophic microorganisms (methanogenic archaea, sulphate-reducing and acetogenic bacteria). Reductive acetogenesis, i.e. acetate synthesis from $\mathrm{CO}_{2}$ reduction, was demonstrated to be an active process of $\mathrm{H}_{2}$ disposal in the colon of non-methane excreting subjects, harboring low numbers of methanogens $[1,2]$. The taxonomy and phylogeny of the $\mathrm{H}_{2} / \mathrm{CO}_{2}$-utilizing acetogenic strains isolated from non-methane producing human faeces, showed the important diversity of this microbial population [3]. These acetogenic bacteria belong to different genera including Clostridium, Ruminococcus and Streptococcus.

The aim of the present work was to investigate the characteristics of $\mathrm{H}_{2} / \mathrm{CO}_{2}$ metabolism in four of these acetogenic species (two Clostridium spp., a strain of Streptococcus and Ruminococcus hydrogenotrophicus $\mathrm{sp}$. nov.[4]). The four strains were able to use $\mathrm{H}_{2} / \mathrm{CO}_{2}$ as sole energy source to produce acetate. Incorporation of ${ }^{13} \mathrm{CO}_{2}$ into acetate by these species further demonstrated the utilization of the reductive pathway of acetogenesis. Chemiosmotic mechanisms of ATP generation seemed to be involved during acetate synthesis. It is likely that those of Clostridium F5a15 were sodiumdependent in contrast to the other strains. The minimal threshold of $\mathrm{H}_{2}$ uptake in these acetogens was higher than that of the predominant colonic methanogen, Methanobrevibacter smithii. Autotrophic metabolism in acetogenic strains was modulated by yeast extract, tryptone or rumen fluid. Vitamins were required for $\mathrm{H}_{2} / \mathrm{CO}_{2}$ metabolism in most strains ex- cept Clostridium M5a3. The presence of glucose also modulated $\mathrm{H}_{2} / \mathrm{CO}_{2}$ utilization by these acetogens but the conditions in which they were able to co-utilize both glucose and $\mathrm{H}_{2} / \mathrm{CO}_{2}$ varied according to the species.

1. Lajoie SF, Bank S, Miller TL, Wolin, MJ (1988) Appl Environ Microbiol 54, 27232727

2. Bernalier A, Lelait $M$, Rochet $V$, Grivet JP, Gibson GR, Durand, M (1996) FEMS Microbiol Ecol 19, 193-202

3. Bernalier A, Rochet V, Leclerc M, Dore J, Pochart P (1996) Curr Microbiol 33, 9499

4. Bernalier A, Willems A, Leclerc M, Rochet V, Collins MD (1996) Arch Microbiol 166, 176-183

\section{Study of the adaptation of the ru-} men ecosystem to the antimethanogenic effect of monensin measured in vivo. JP Jouany, B Lassalas (INRA, Station de Recherches sur la Nutrition des Herbivores, Centre de Clermont-Theix, 63122 Saint GenèsChampanelle, France)

Monensin is known as a potent antimethanogenic agent in the rumen. According to the literature, its effect persists throughout treatment [1], or decreases quickly and disappears approximately two weeks after the start of the treatment $[2,3]$.

Four adult sheep fitted with a special rumen cannula allowing rumen gas sampling [4] just before (T0), $2 \mathrm{~h}$ after (T2) and $5 \mathrm{~h}$ after feeding (Ts) were used. Animals were fed a mixed diet of grass hay $(950 \mathrm{~g})$ and barley $(400 \mathrm{~g})$ given twice daily. During period 1 (15 days) sheep 